\title{
Fish habitat suitability and community structure in the equatorial Lake Naivasha, Kenya
}

\author{
D. O. Oyugi - K. M. Mavuti - P. A. Aloo • \\ J. E. Ojuok · J. R. Britton
}

Received: 6 April 2013/Revised: 20 November 2013/Accepted: 7 December 2013/Published online: 19 January 2014

(C) The Author(s) 2014. This article is published with open access at Springerlink.com

\begin{abstract}
Habitat suitability indices indicate how fish species respond to different habitat types. We assessed effects of habitat characteristics on fish distribution in an equatorial lake, Lake Naivasha, Kenya, where habitats vary according to substrate, depth and turbidity. Using monthly data between 2008 and 2010 using multi-mesh gill nets, catch per unit effort was used as a relative abundance measure to identify how habitat variables drive fish distribution. The focus was on commercial fishes: two introduced species (Cyprinus carpio and Micropterus salmoides) and two naturalised species (Oreochromis leucostictus and Tilapia zillii). Analyses revealed distinct preferences for different habitat variables by all commercial species except for C. carpio. For example, O. leucostictus preferred shallow waters with silt-clay
\end{abstract}

Handling editor: J. M. Melack

D. O. Oyugi $(\bowtie)$

School of Spatial Planning and Natural Resource

Management, Jaramogi Oginga Odinga

University of Science and Technology, P.O. Box 210,

Bondo 40601, Kenya

e-mail: doyugi2001@yahoo.co.uk

K. M. Mavuti

School of Biological Sciences, University of Nairobi,

P.O. Box 30197, Nairobi 00100, Kenya

P. A. Aloo

Department of Aquaculture and Fisheries, Karatina

University, P.O. Box 1957, Karatina 1010, Kenya substrates whilst $M$. salmoides preferred deeper waters with sandy/rocky substrates. Conversely, C. carpio showed no specialised habitat requirements. Niche overlaps were significantly lower between $O$. leucostictus and its respective sympatric species than between other species, a likely result of its territorial behaviour. The continued environmental degradation of Lake Naivasha may imperil the preferred habitats of the niche restricted $M$. salmoides, O. leucostictus and T. zillii. By contrast, the ubiquity of $C$. carpio may facilitate their invasion, and consequently sustain their dominance in the lake's commercial fishery.

Keywords Habitat suitability index . Occurrence probability · Niche overlap . Habitat use 


\section{Introduction}

The spatial and temporal distribution of fish communities are determined by their functional requirements in relation to a range of abiotic factors in their environment. Distributions are thus often determined by niche requirements that result in the development of fish functional guilds (Noble et al., 2007). The guilds in turn are intricately governed by trophic dynamics and life-history requirements. Studies suggest fish spatial distribution and habitat preferences are a function of habitat stability and migration patterns (e.g. by LoweMcConnel, 1999; Silvano et al., 2000). For example, it has been recorded that migration in fishes accounts for their seasonal variability either in pursuit of food or for reproduction (Hugueny \& Paugy, 1995; Belliard et al., 1997; Lowe-McConnel, 1999; Silvano et al., 2000). It also facilitates access to refugia, especially from predation, and can assist the avoidance of niche competition (Silvano et al., 2000). The net result is fish species generally developing well-defined spatial and trophic niches, and community assemblages and guilds (Hugueny \& Paugy, 1995).

Moreover, understanding the diversity, density and distribution of fish populations, and the factors that drive their processes, is important in facilitating suitable fish stock management interventions. For example, policy decisions on closed seasons, and restricted areasusually spawning areas-are only reached with sound knowledge on spatial and temporal distribution and utilisation of fish habitats (Hugueny \& Paugy, 1995). Habitat characteristics, especially water depths and substrate structure, particularly play a significant role in explaining lacustrine fish spatial distributions, for example, Carlander (1955) reporting a negative relationship between fish community standing crop and maximum lake depth. The determination of such relationships is important in lakes, where environmental conditions tend to be in a state of flux due to variability in climate and the result of on-going human activities. An example of such a lake is Lake Naivasha, Kenya, where despite RAMSAR status, the lake remains subject to high abstraction rates in support of industry and agriculture that impacts lake level as it results in the lake increasingly being disconnected from its tributary rivers (Britton et al., 2010a). Consequently, knowledge on the spatial distribution of fish and their relationship with physical habitat structure is important in the development of relevant fishery management strategies.
Fig. 1 A map of Lake Naivasha and its watershed (inset) showing the six survey sites: $R M$ River Mouth, $M L$ Middle Lake, $C L$ Crescent Lake, $S B$ Sher Bay, $O B$ Oserian Bay, $H P$ Hippo Point

All the fish species present in Lake Naivasha are non-indigenous with introductions commencing in the 1920s. Aplocheilichthys antinorii (Vinc.), the only indigenous fish of the lake, was last reported in 1962, and is presumed to have been extirpated through predation pressure from introduced largemouth bass Micropterus salmoides (Lacépède) (Muchiri \& Hickley, 1991). The other species present in the lake are common carp Cyprinus carpio L., the tilapiine species Oreochromis leucostictus (Trewavas) and Tilapia zillii (Gervais), and Barbus paludinosus (Boulenger). Although Oreochromis niloticus L. has recently also been introduced into the lake, they were not present in the samples of this study. Even though the fish community of the lake has received a great deal of research attention (e.g. Siddiqui, 1979; Dadzie \& Aloo, 1990; Muchiri \& Hickley, 1991; Muchiri et al., 1995; Hickley et al., 2002; Britton et al., 2007; Ojuok et al., 2007), there have been few studies focusing on the spatial distribution of the fish species and how these relate to the habitat variables of the lake. Comparatively, more comprehensive assemblage studies have focused on benthic macro-invertebrates (Clark \& Beeby, 1989; Raburu et al., 2002), zooplankton (Harper, 1987; Mavuti, 1990), phytoplankton (Hubble, 2000; Hubble \& Harper, 2002), and decapods (Oluoch, 1990; Hickley \& Harper, 2002; Smart et al., 2002). Consequently, the aim of this paper was to assess the spatial differences in fish species distributions of Lake Naivasha in relation to their habitat suitability and niche partitioning with a view to providing relevant information to assist the formulation of fisheries management decisions and the development of policy frameworks.

\section{Materials and methods}

Study area

Lake Naivasha is situated $190 \mathrm{~km}$ south of equator (i.e. at $0^{\circ} 45^{\prime} \mathrm{S} ; 36^{\circ} 21^{\prime} \mathrm{E}$ ), within the eastern arm of the Great Rift Valley. It is approximately 1,890 m.a.s.l. (Fig. 1), and has a mean surface area of $145 \mathrm{~km}^{2}$ with a highly fluctuating mean depth of between 3 and $6 \mathrm{~m}$ 


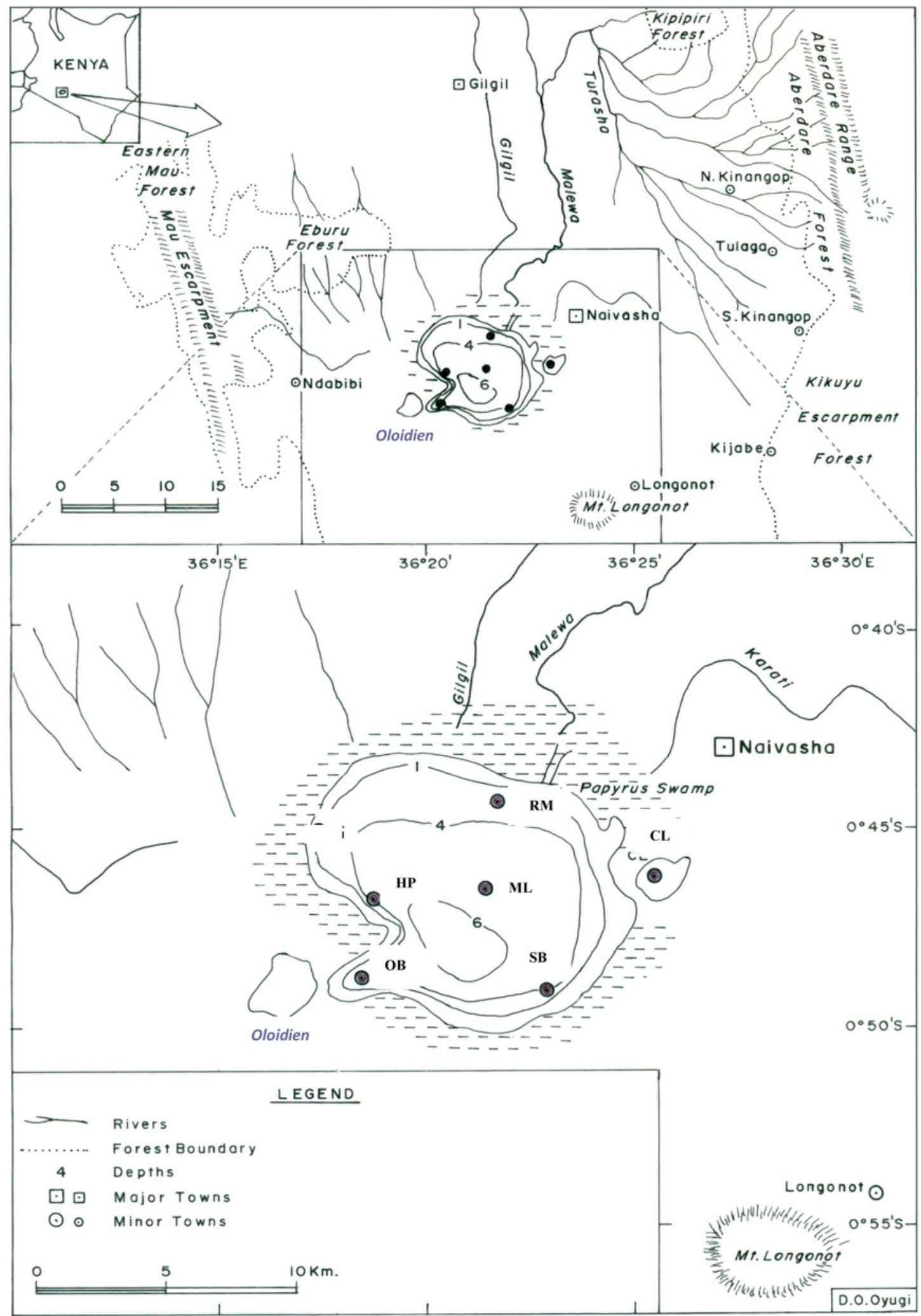


depending on a lake level (Becht $\&$ Harper, 2002). The lake level is, in turn, driven by hydrological patterns in the larger Aberdare catchment and the intertropical convergence zone (Becht \& Harper, 2002). Despite its declaration as a RAMSAR Site in 1995 (Wetlands International, 2003), the lake and its catchment is still faced with considerable anthropogenic pressures that have resulted in eutrophication, habitat degradation, invasive species, lake level fluctuation and excessive fishing pressure (Kitaka et al., 2002; Harper \& Mavuti, 2004; Britton et al., 2007; Oyugi, 2012).

Field sampling techniques

Fish sampling was completed monthly between 2008 and 2010 covering six different locations (Fig. 1), and spanned both wet and dry seasons. The survey locations represented six major habitat types of the lake namely: River Mouth (RM), representing a shallow $(\sim 135 \mathrm{~cm})$ habitat, characterised by a muddy substrate, often with rotting allochthonous debris from the River Malewa; Middle Lake (ML) representing open waters $(\sim 360 \mathrm{~cm}$ deep), characterised by a muddy substrate, with strong wind action also evident; Crescent Lake (CL), which was deep $(\sim 1,800 \mathrm{~cm})$ and characterised by a sandy substrate with rocky shore with minimal wind action; Sher Bay (SB), an extensive shallow bay ( $\sim 220 \mathrm{~cm})$ fringed with Cyperus papyrus; Oserian Bay (OB), a semi-isolated shallow bay $(\sim 160 \mathrm{~cm})$ with a muddy substrate and fringed with $C$. papyrus; and Hippo Point (HP), representing the deepest part of the open lake $(\sim 800 \mathrm{~cm})$, was characterised by rocky-sandy substrate (Fig. 1). Note the Crescent Island site was isolated from the main lake during the study as a result of prolonged drought.

Sampling the fish communities of large tropical lakes is inherently difficult and Lake Naivasha is no exception. Obtaining quantitative population estimates is not feasible due to factors including restricted access to the lake shore making seine netting impossible and the inefficiency of electric fishing in large water bodies. The considerable presence of hippopotami Hippopotamus amphibius in the lake also compromises the safety of sampling teams if they are required to spend extended periods in the lake. Consequently, previous studies on lake Naivasha have employed multi-mesh gillnets to provide relative measures of fish abundance using catch per unit effort (number of fish sampled per hour per gill net; $c f$.; Hickley \& Harper, 2002; Hickley et al., 2002; Britton et al., 2007, 2010b). Although not providing quantitative abundance estimates, through use of standardised gill net mesh sizes in each survey and sampling the same locations, these studies were able to infer temporal relationships in the relative abundance of the species in the fish community. This facilitated the measurement of changes in the fish community of the lake when collecting other forms of abundance estimates was impossible. Consequently, in this study, fish samples were also collected through deployment of a standard set of gill nets using mesh sizes of 1, 2, 3, 4, 5, 6 and 7 inches (knot-to-knot). These were set on a monthly basis at 08.00 and always lifted after $4 \mathrm{~h}$ fishing.

Once the nets were lifted, the fish were removed, sorted and identified to species level and counted. At each sampling site, turbidity was determined by Secchi disc, and surface water temperature, $\mathrm{pH}$ and electrical conductivity were determined at each sampling site using a hand-held waterproof Hanna Combo $\mathrm{pH} \&$ EC meter. Corresponding substrate samples to determine substrate characteristics were taken by a $15 \times 15 \mathrm{~cm}^{2}$ Eckman grab. Lake level data were obtained from Water Resource Management Authority (WRMA) of the Ministry of Water Development.

Analysis of relative abundance, lake level and substrate type

The number of fish captured per species per month and sampling location was used to calculate catch per unit effort (CPUE) as per Hickley et al. (2002) and Britton et al. (2007). The abundance data were subsequently tested against lake level as a surrogate of changing environmental conditions by use of least square techniques. As monthly lake level was only expected to register a possible impact on fish abundance in the subsequent months; therefore, fish monthly CPUE data at time $t$ were correlated with lake level data at time $(t-1)$. In the laboratory, an Octagon 200 test sieve shaker was used to analyse sediment grain size which were separated as sand $(>125 \mu \mathrm{m})$, silt $(125-63 \mu \mathrm{m})$ and clay $(<63 \mu \mathrm{m})$, as described by Buchanan (1971).

Analysis of fish habitat suitability

Initially, univariate least square models were performed on CPUE to determine the most important habitat variables of fish relative abundance for the species C. carpio, M. salmoides, O. leucostictus and $T$. zillii (due to their importance in the commercial 
fishery). Given the lentic conditions and the model outputs then lake depth, water transparency and substrate type were selected as the most important habitat variables (based on regression $r^{2}$ and significance levels) for habitat suitability index (HSI) analysis. This followed the procedure modified from Bovee (1986) as:

(i) values of the three habitat variables: depth, water transparency and substrate structure, were divided into size classes, upon which, class midpoints were determined and frequency of utilisation $(U)$ computed as the total sum of CPUE within each class interval (CI). Habitat variable availability $(A)$ within each size class was computed as percentage occurrence of that variable class across the six sampling sites;

(ii) preference for habitat variable class interval was consequently computed from estimated relative frequencies of utilisation and habitat availability as:

$P_{\mathrm{i}}=\frac{U_{\mathrm{i}}}{A_{\mathrm{i}}}$,

where $P_{\mathrm{i}}$ is the relative preference value of target species for a specific interval of the measured habitat variable, $U_{\mathrm{i}}$ is the $\%$ of utilisation of a specific class interval of the measured variable, here calculated as: (CPUE at CI/total CPUE) $\times$ $100 ; A_{\mathrm{i}}$ is the $\%$ availability of a specific class interval of the habitat variable at the time of sampling. This was determined as \% occurrence of that habitat variable CI across the six sampling sites. For example, if a depth of 300-500 cm was achieved in only three sites out of the six sites, then $A_{i}$ was computed as $3 / 6 \times 100$ etc.

(iii) all habitat preferences were normalised to a possible maximum sealing of 1.0 ,

(iv) to express habitat suitability curves, polynomial regression models were performed, based on relative preference values $\left(P_{\mathrm{i}}\right)$ and midpoint value of each habitat variable class. For each variable, several polynomial functions-at different orders-were considered for each fish species, and the best model for each function was taken based on the model coefficient $r^{2}$ $(>0.6)$ and its significance level $(P<0.05)$.

To predict the occurrence of the four fish species in the different habitat types of the lake, the probability of their occurrence according to the habitat variables were determined using their presence/absence data. Binary logistic regression analyses were performed to determine the constant ' $a$ ' and the regression model coefficients ' $b$ ' and ' $c$ ' for depth and water transparency, respectively. These were then used in a probability equation to determine the probability $(P)$ of catching a fish of that species according to depths $(Z)$ and water transparency (Secchi depths) (d) (Delaney \& Leung (2010):

$P=\frac{e^{(a+b Z+c d)}}{1+e^{(a+b Z+c d)}}$

The final assessment of how habitat variables influenced spatial fish distribution and the interactions of each species in the lake, the habitat overlap index (T) was determined after Schoener (1983):

$T=1-0.5 \sum\left|P x_{h_{i}}-P y_{h_{i}}\right|$

where $P x_{h_{i}}$ and $P y_{h_{i}}$ were determined as the proportion of abundance (CPUE) of species $X$ and $Y$ at a given site $\left(h_{i}\right)$ in relation to the total abundance from all the sites per season.

Statistical analysis

Both biotic and abiotic data were tested for normality before any parametric tests were performed. Here, normality and homoscedasticity of data were verified by Kolmogorove-Smirnove distribution test (Pallant, 2007), upon which non-parametric data were either log-transformed, i.e. for counts, or fourth-root transformed for ratios and measurements. All the statistics were completed by SPSS v. 18. Where errors were given around mean values, they represented $95 \%$ confidence limits.

\section{Results}

Fish relative abundances (i.e. CPUE) differed significantly between species and sites, except for C. carpio, which showed non-significant spatial variability across the entire lake (ANOVA: $F_{5,65}=1.21$, $P>0.05$ ) (Fig. 2). The CPUE of $C$. carpio and $O$. leucostictus was relatively low in the rocky lagoonal habitat at Crescent Lake, while $M$. salmoides was hardly recorded in the open waters and river mouth 
Fig. 2 Spatial variability of relative abundance (CPUE) of C. caprio, O. leucostictus, T. zillii and M. salmoides in six survey sites: $R M$ River Mouth, $M L$ Middle Lake, $C L$ Crescent Lake, $S B$ Sher Bay, $O B$ Oserian Bay, $H P$ Hippo Point in Lake Naivasha
M. salmoides

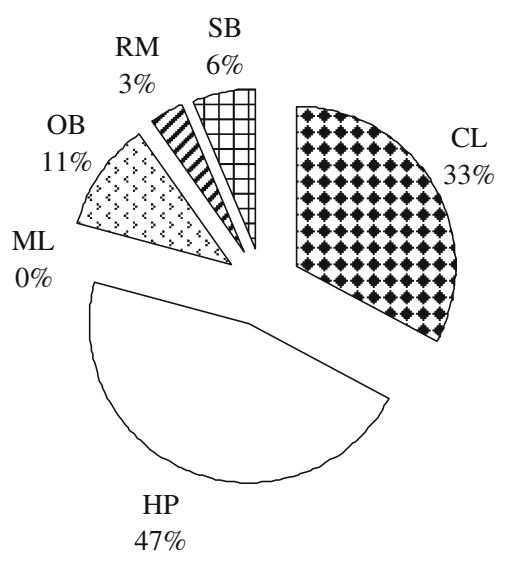

T. zillii

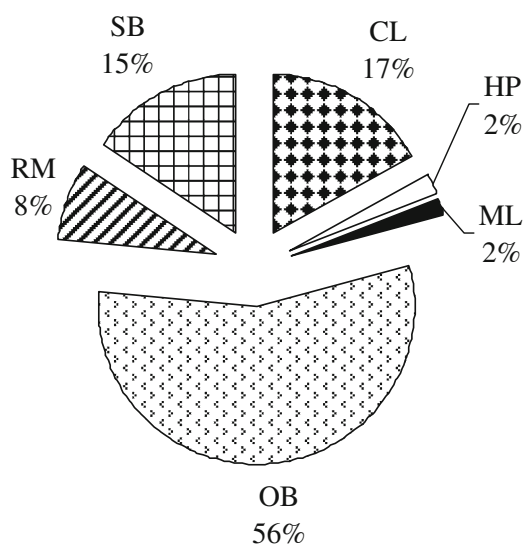

\section{O. leucostictus}

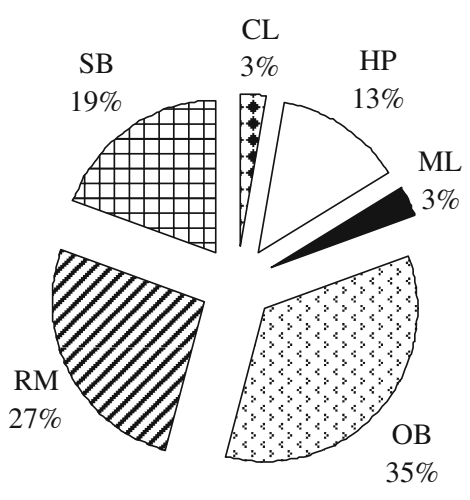

C. carpio

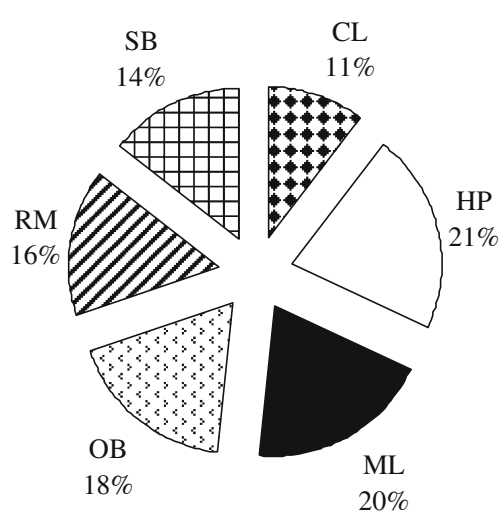

habitats. Similarly, there was no significant seasonal variability in all the fish catches in pooled CPUE from all the survey sites (ANOVA: $M$. salmoides: $F_{3,20}=$ 0.94; $\quad P>0.05 ; \quad O$. leucostictus: $\quad F_{3,20}=1.51$; $P>0.05 ;$ T. zillii: $\left.F_{3,20}=1.15 ; P>0.05\right)$, except for $C$. carpio (ANOVA: $F_{3,20}=8.40 ; P<0.01$ ). Bonferroni multiple comparisons showed significantly depressed CPUE for $C$. carpio during the long rains in April, in comparison with short dry spell (in July) $(P<0.05)$, and short rains (in October) $(P<0.01)$. Multiple comparisons, however, revealed no significant variation in carp CPUE between long rains and long dry spell $(P>0.05)$. However, seasonal variation in lake level registered a positive correlation with CPUE of $C$. carpio $\left(R^{2}=0.63 ; \quad F_{1,17}=29.45\right.$; $P<0.01)$ and $T$. zillii $\left(R^{2}=0.76, F_{1,12}=38.69\right.$; $P<0.01$ ), but not with the CPUE of $O$. leucostictus
$\left(R^{2}=0.06 ; F_{1,20}=1.38 ; P>0.05\right)$ and $M$. salmoides $\left(R^{2}=0.03 ; F_{1,20}=0.001, P>0.05\right)$ (Fig. 3).

Very low habitat suitability indices and consequent undefined suitability curves typified unrestricted occurrence of C. carpio in the entire lake (Fig. 4). By contrast, the other fish species showed strong preferences in combinations of habitat variables. $O$. leucostictus exhibited a strong preference for shallow waters (Fig. 4), especially with a silt and clay substrate, whereas M. salmoides preferred deeper waters with sandy-rocky substrates (Fig. 5). Whilst the low number of data points prevented further testing on substrate structure, M. salmoides and O. leucostictus showed, albeit only by magnitude, higher preference for sandy and clay substrates, respectively. For $T$. zillii and C. carpio, there was no apparent substrate preference. 
(a)

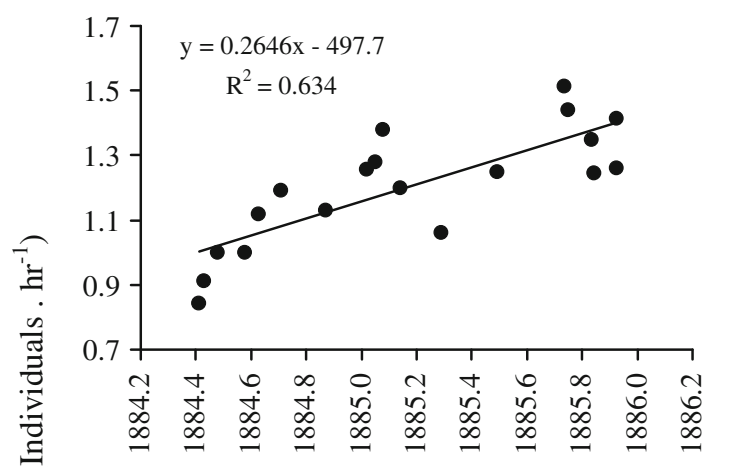

(c)

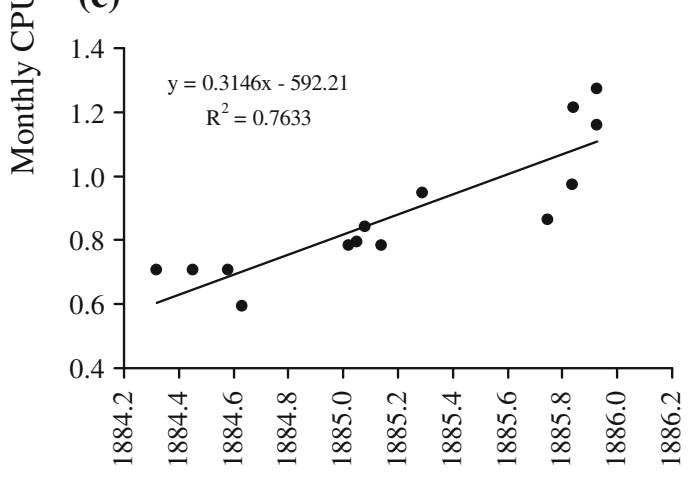

(b)

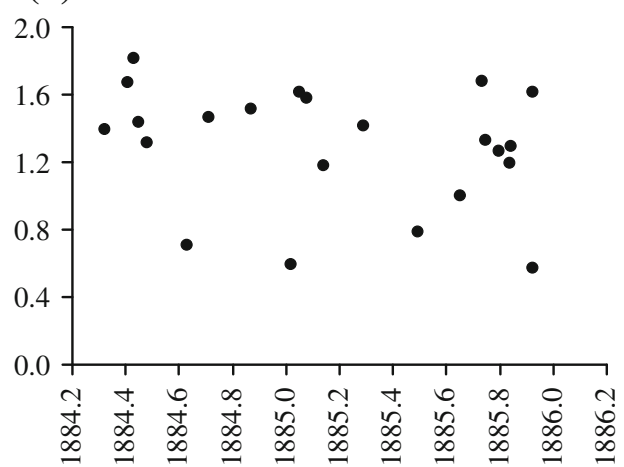

(d)

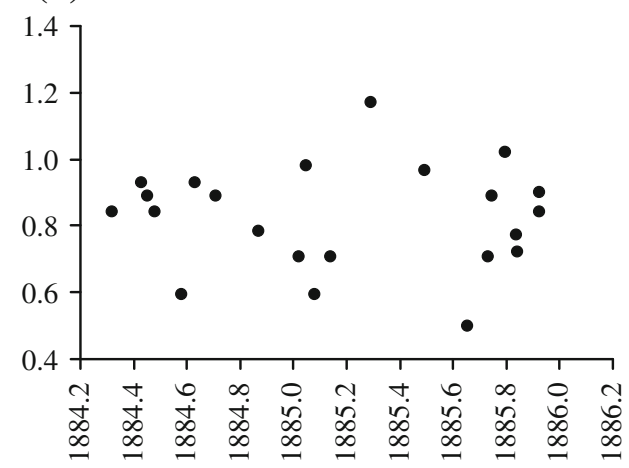

Mean monthly lake level (m.a.s.l) at time ( $t-1)$

Fig. 3 Relationship between lake level and relative abundance (CPUE) of C. carpio (a); O. leucostictus (b); T. zillii (c) and M. salmoides (d) in Lake Naivasha

The probability of catching M. salmoides in a gill net sample was high (i.e. $>80 \%$ ) in deeper (i.e. $>500 \mathrm{~cm}$ ) and clearer (i.e. $>80 \mathrm{~cm}$ Secchi depth) waters (Fig. 6). The probability of catching $T$. zillii at water depths of more than $200 \mathrm{~cm}$ was, however, less than $80 \%$ and this declined further as water depth increased (Fig. 6). Similarly, the chances of catching O. leucostictus at water depths $>300 \mathrm{~cm}$ also diminished with advancing depths. Unlike M. salmoides, water transparency was a poor predictor of $T$. zillii and O. leucostictus distribution.

The Fish habitat overlap index $(T)$ showed significant spatial interaction between all the species (i.e. $T>0.6$ ) (Fig. 7). There was, however, no significant seasonal overlap variability between species (ANOVA: $F_{3,20}=0.10, P>0.05$ ). O. leucostictus had significantly weaker spatial overlap with all the other three sympatric species low (ANOVA: $F_{5,18}=4,718.74 ; P<0.01$ (Fig. 7).

\section{Discussion}

The outputs of the study revealed distinct habitat preferences in the fish species of Lake Naivasha, other than in the invasive C. carpio. Shallower waters, particularly over silt and clay, were preferred by $O$. leucostictus, whereas $M$. salmoides preferred the lake habitats with deeper and clearer water. This suggests strong structuring of aspects of the fish community according to their habitat preferences. Nevertheless, these outputs might be being compromised by the methodology used to collate the data. In particular, the fish abundance data was based on sampling with gill nets that have inherent bias in their capture of certain fish species and sizes according to the mesh size (e.g. Hamley, 1975). However, in previous fish-based studies of Lake Naivasha, a number of authors have overcome this problem in two ways: (i) through use of a standard set of gill net meshes and net sizes over time 
(a)

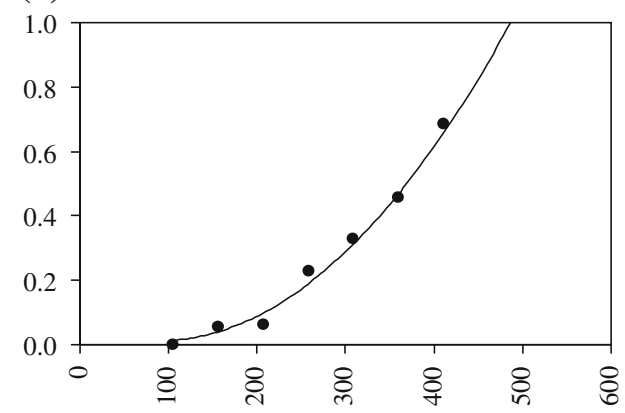

(b)

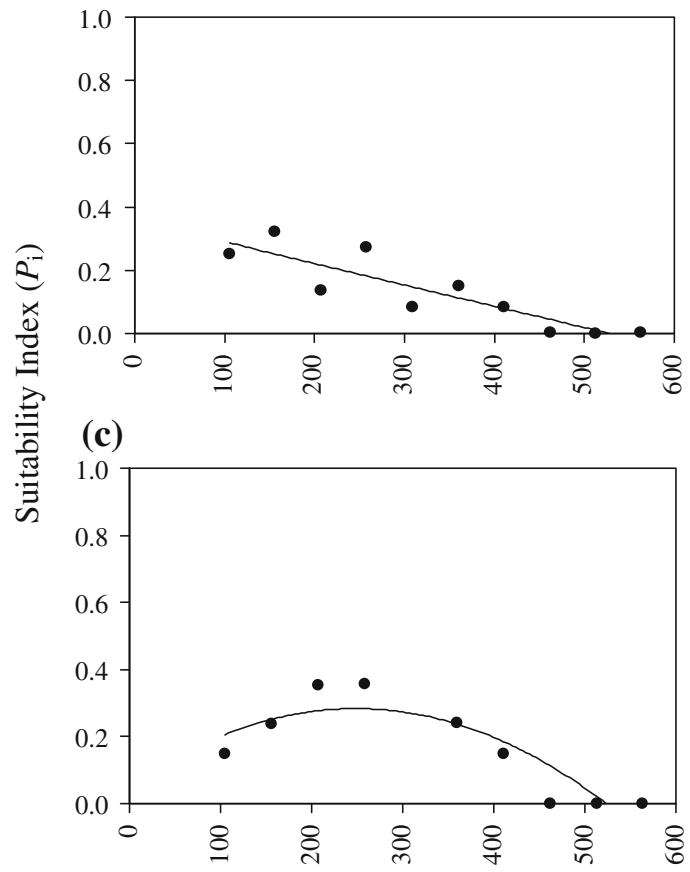

(d)

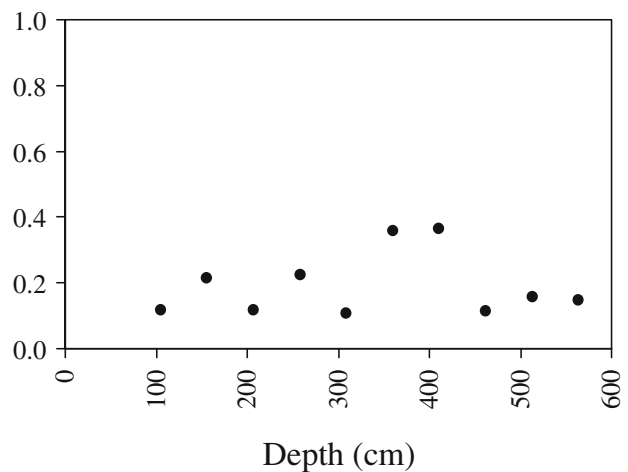

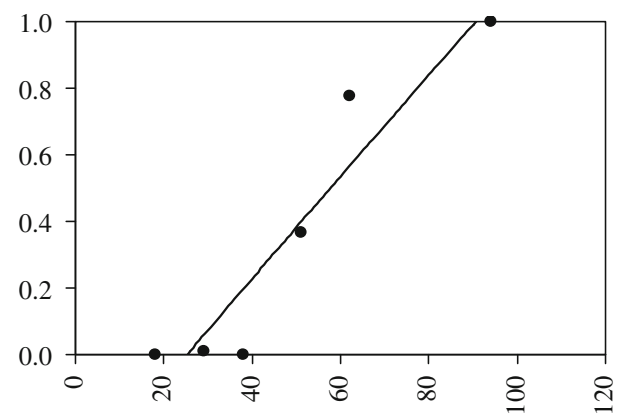
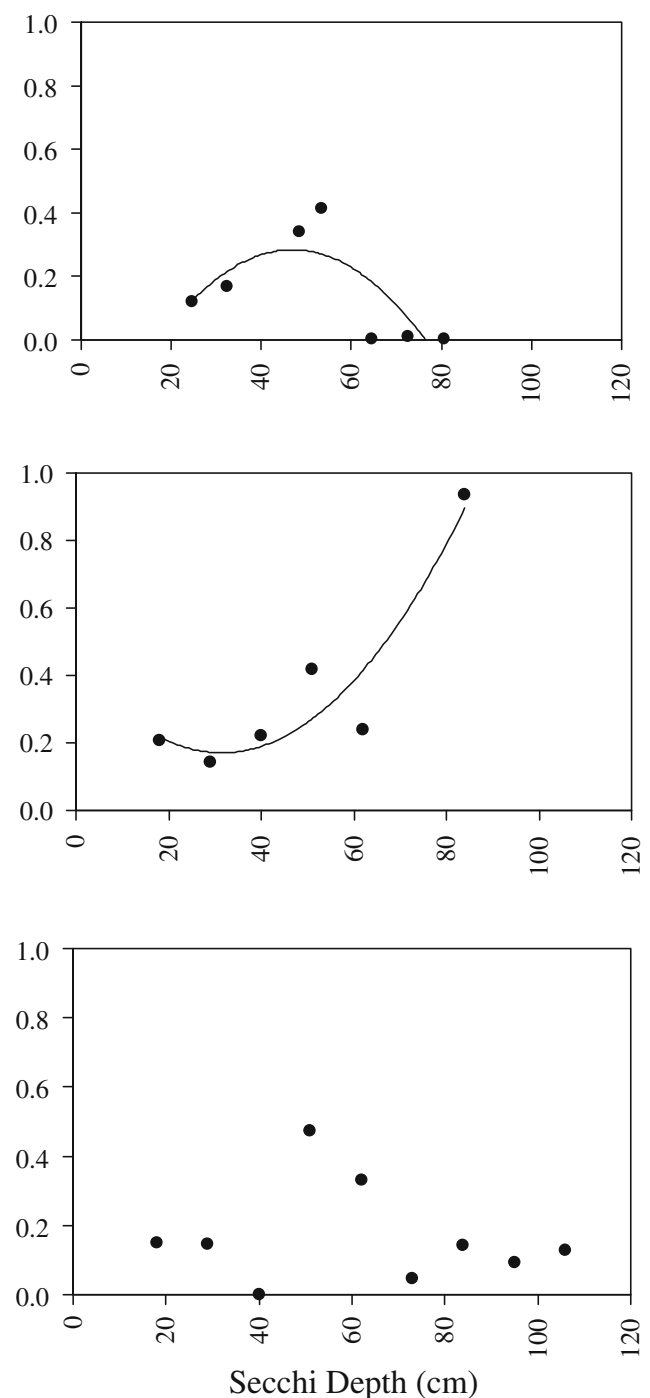

Fig. 4 Habitat suitability curves of four commercial fish species in Lake Naivasha based on polynomial regression models of depth (left column), and water transparency (right column) for: a M. salmoides, b O. leucostictus, c T. zillii and d C. carpio 
(a)
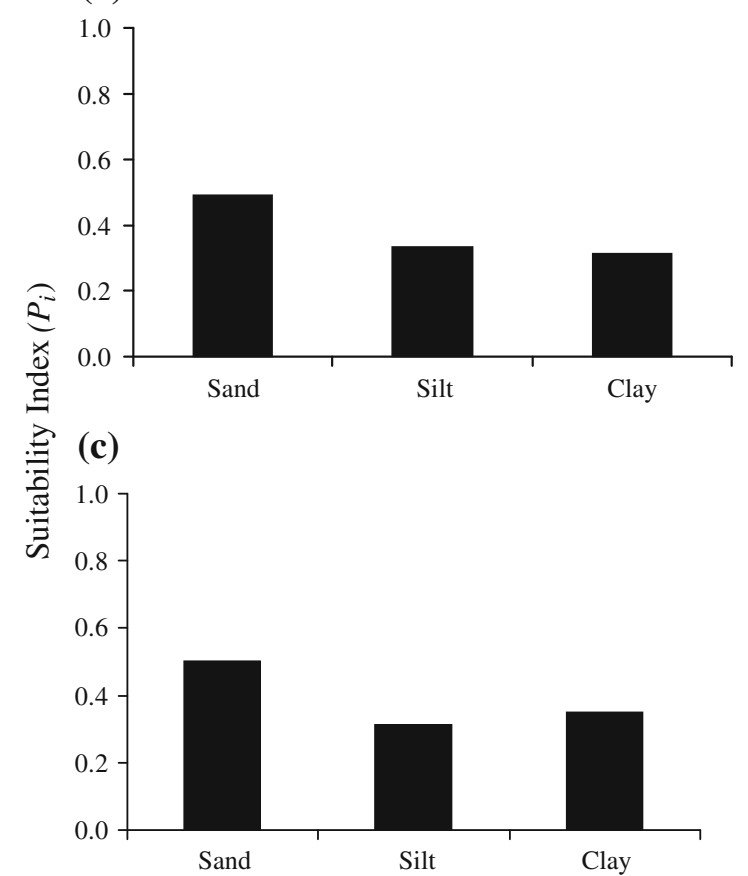

(b)

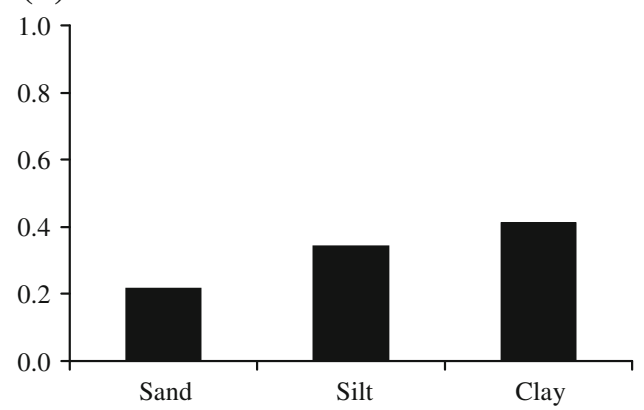

(d)

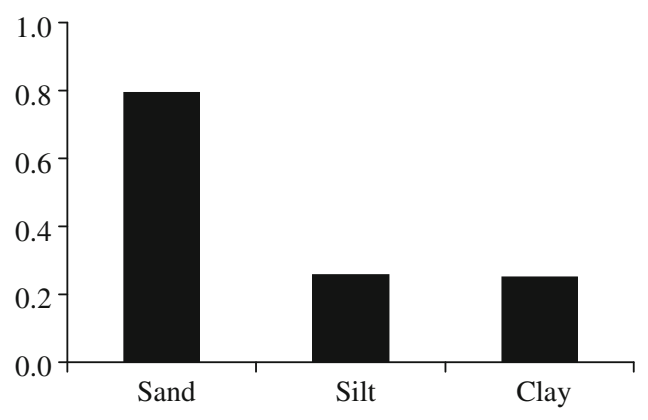

Substrate Structure

Fig. 5 Effects of substrate structure (clay, silt and sand) on habitat suitability for four fish species: a M. salmoides; b O. leucostictus; c T. zillii and d C. carpio, of Lake Naivasha

to account for the differential abilities of different mesh sizes to catch different components of the fish community (Hickley \& Harper, 2002; Hickley et al., 2002); and (ii) by the use of catches of fish in each survey to produce a relative measure of fish abundance, i.e. catch per unit effort as the number of fish per hour per gillnet, where 'gillnet' represents all of the mesh sizes fished (Hickley \& Harper, 2002; Hickley et al., 2002; Britton et al., 2007). Although the data are unlikely to be suitable for comparison with catches from other lakes, the standardised methodology and output provides data that can arguably be compared reliably between sampling sites and across time. Differences in the catches of fish are thus not due to differences in the ability of the nets to catch the fish but rather the abundance of the fish at that site. Consequently, there is confidence that the habitat associations and patterns in niche partitioning were representative of the true patterns in the lake.

The ubiquitous occurrence of $C$. carpio in all sampling sites contrasted the spatially restricted assemblage of the other fishes. That $C$. carpio was able to be present across a wide range of habitat variables might be considered advantageous in its ability to maintain a large, invasive population. The carp is principally a benthic detritivore (Khan et al., 2003; Britton et al., 2007; Oyugi, 2012), and its ubiquity in the lake may not only facilitate its autoecological processes (e.g. access to habitat-restricted food resources), but it may also facilitate their survival schemes in case of specific localised environmental disruptions. For example, when C. carpio was reported to have quickly rejuvenated its population following sitespecific mass kills in some parts of Lake Naivasha in 2010 (Oyugi, 2012), which was attributed to localised depletion of dissolved oxygen in the lake, unaffected stocks of C. carpio in areas that did not experience the hypoxia enabled their rapid population re-establishment (Oyugi, 2012). The high abundance of $C$. carpio across all types of habitats in the lake also negates the initial presumption by Muchiri et al. (1995) that any new fish entries into Lake Naivasha would not survive the considerable environmental variability which characterises the lake at present.

Contrary to Weber et al. (2010), who reported from upper Midwest United States that $C$. carpio population densities increased with depth, the fish transcended all 
(a)

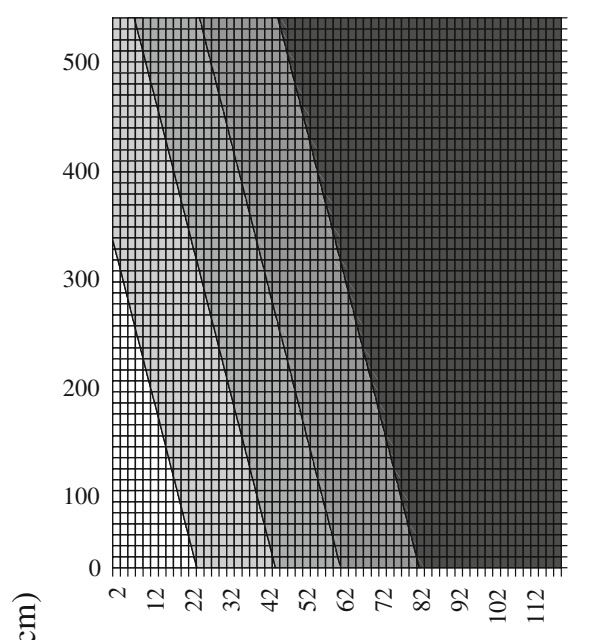

(c)

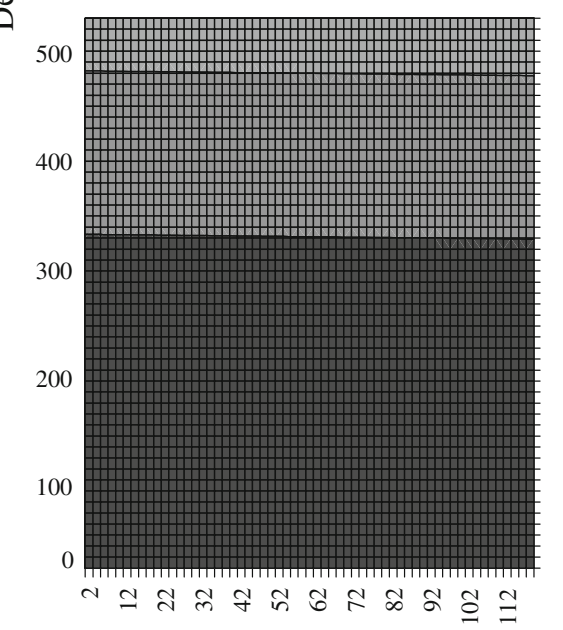

(b)

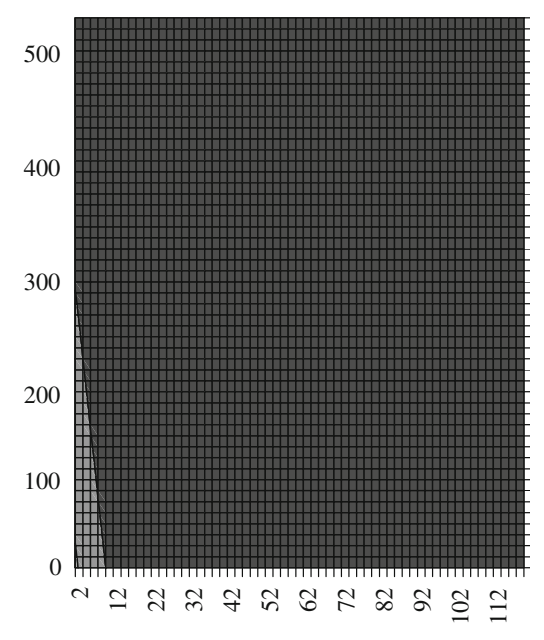

(d)

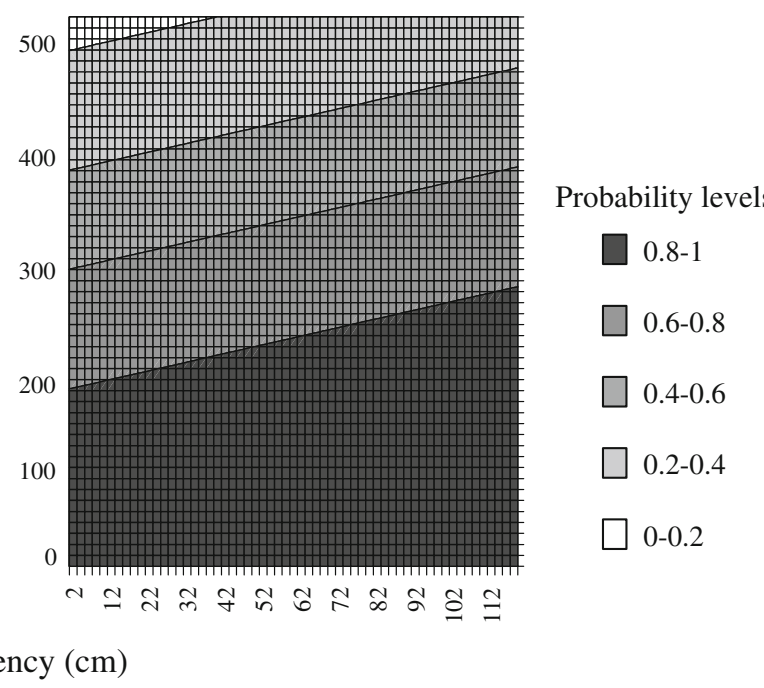

Fig. 6 Contour plots of probability of occurrence of fish species: M. salmoides (a), C. carpio (b), O. leucostictus (c) and T. zillii (d), at various depths and water transparency levels in Lake Naivasha

depths and substrate types in Lake Naivasha, with relatively similar values in relative density. Conversely, M. salmoides' population in the lake displayed a niche-restricted spatial distribution, where its stocks were only pronounced in areas with sandy/ rocky substrates, a pattern similar to that exhibited by T. zillii. O. leucostictus, on the other hand, preferred muddy substrates, presumably due to its favoured detritivorous feeding strategy (Oyugi, 2012). In Lake Victoria Basin, the origin of the Naivasha T. zillii population (Siddiqui, 1977), the species also showed a strong affinity for rocky outcrops and rocky shores. As reported by Muchiri et al. (1995), this habitat preference by $T$. zillii may be explained by its nest spawning territoriality and omnivorous feeding habit.

The probability of occurrence analysis was able to predict the presence/absence of $M$. salmoides in the different habitats of Lake Naivasha. The probability was fundamentally driven by water depths and water transparency. M. salmoides is a highly predatory fish and principally relies on water clarity as it forages by sight (Britton et al., 2010b). Their diet composition, which has recently shifted in Lake Naivasha from a crayfish-based diet to predominantly fish-based diet 


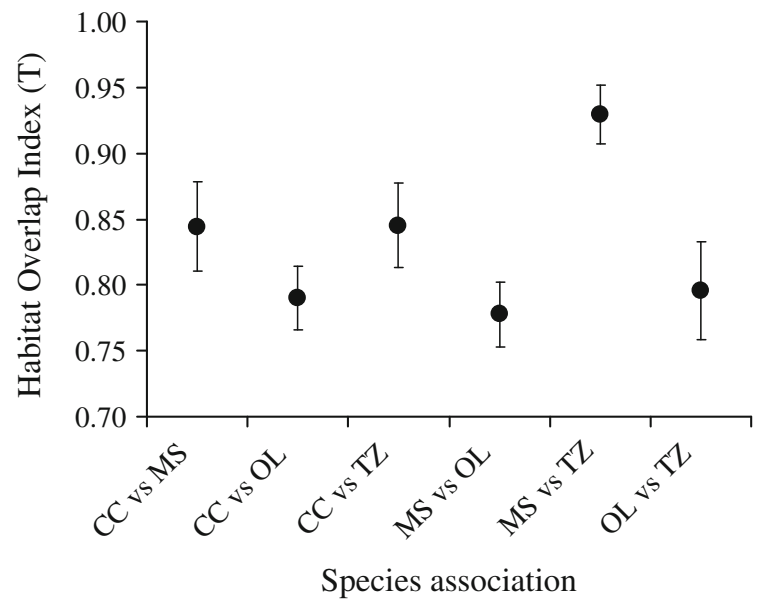

Fig. 7 Mean ( \pm SE) niche overlap between four fish species: $C$. carpio (CC), O. leucostictus (OL), M. salmoides (MS) and T. zillii (TZ) in the major habitats of Lake Naivasha

(Britton et al., 2010b; Oyugi, 2012), lends support to the ecological sustenance of discrete bass populations in rocky and deeper habitats characterised by clearer waters that assists their sight feeding (Britton et al., 2010b). Such environmental conditions were only available at Crescent Lake (CL) and Hippo Point (HP), resulting in their two disjunctive populations in the lake. Iguchi et al. (2004) also revealed that in its native range in eastern North America, the bass preferred quiet and clear waters with abundant vegetation cover.

Even though earlier works (e.g. Hickley et al., 2004) depicted T. zillii as capable of venturing into deeper waters, this may only span up to $c .300 \mathrm{~cm}$ deep, beyond which the depths become unsuitable, probably constrained by light extinction due to high amount of suspended solids. Studies by Muchiri et al. (1995), Hickley et al. (2002), Britton et al. (2007), Ojuok et al. (2007), Britton et al. (2010b) and Oyugi et al. (2011a, b), portrayed a rapid decline in the populations of the two tilapiines (O. leucostictus and T. zillii). As was evident from this study, this would partly be due to their habitat-restricted distribution mainly to shallow silt-clay substrate that is usually available only in the littoral zone. Currently, the two tilapiines seldom contribute to the commercial landings from Lake Naivasha where $C$. carpio has taken $c$. $100 \%$ dominance (AFB, 2009). Moreover, the relatively low spatial niche-overlap between $O$. leucostictus and its sympatric species in the lake was likely to be due to its territoriality nature. Being a cichlid, $O$. leucostictus strongly and aggressively guards its territory (Oyugi et al., 2011a, b), and their restriction to shallow-muddy habitats may expose such territories to the disruptions caused by the rapidly increasing populations of $C$. carpio which traversed the entire lake. The inshore preference by the two cichlids would also subject them to illegal fishers who had been observed to specifically target the tilapiines in the shallow inshore habitats using gillnets with illegal mesh sizes (Oyugi, 2012). Thus, the outputs of the study should be important in assisting the development of fishery management schemes designed to protect vulnerable fish populations from both being over-exploited by licensed fishers and poached by unlicensed fishers.

Acknowledgments This work was made possible with support from Commonwealth Award to D. O. Oyugi through the British Council. We would also like to sincerely thank the management of Kenya Wildlife Service Training Institute for providing a working space for part of this work. Our sincere gratitude is also due to Mr. Dominic Wambua of the Ministry of Water and Irrigation for the provision of historical lake level data.Open Access This article is distributed under the terms of the Creative Commons Attribution License which permits any use, distribution, and reproduction in any medium, provided the original author(s) and the source are credited.

\section{References}

Annual Fisheries Bulletin (AFB), 2009. Annual Fisheries Report. Naivasha District Fisheries, Report. 28 pp.

Becht, R. \& D. Harper, 2002. Towards understanding the human impact upon the hydrology of Lake Naivasha, Kenya. Hydrobiologia 488: 1-11.

Belliard, J., P. Boet \& E. Tales, 1997. Regional and longitudinal patterns of fish community structure in the Seine River basin, France. Environmental Biology of Fishes 50: 133-147.

Bovee, K. D., 1986. Development and evaluation of habitat suitability criteria for use in the instream flow incremental methodology. Instream flow information paper 21, Report 87 (7). US Fish and Wildlife Service.

Britton, J. R., R. R. Boar, J. Grey, J. Foster, J. Lugonzo \& D. M. Harper, 2007. From introduction to fishery dominance: The initial impact of the invasive common carp Cyprinus carpio in Lake Naivasha, Kenya, 1999 to 2006. Journal of Fish Biology 71: 239-257.

Britton, J. R., D. M. Harper \& D. O. Oyugi, 2010a. Is the fast growth of Micropterus salmoides in an equatorial lake explained by high water temperature? Evidence from a meta-analysis of growth parameters over their range. Ecology of Freshwater Fish 19: 228-238.

Britton, J. R., D. M. Harper, D. O. Oyugi \& J. Grey, 2010b. The introduced Micropterus salmoides in an equatorial lake: a 
paradoxical loser in an invasion meltdown scenario? Biological Invasions 12: 3439-3448.

Buchanan, J. B. \& J. M. Kain, 1971. Measurements of the physical and chemical environment. In Holme, M. A. \& A. D. McInture (eds), Methods for the Study of Marine Benthos. IBP Handbook No. 16.: 30-58.

Carlander, K. D., 1955. The standing crop of fish in lakes. Journal of the Fisheries Research Board of Canada 12: 543-570.

Clark, F. \& A. Beeby, 1989. A study of the macro-invertebrates of Lake Naivasha, Oloidien and Sonnachi, Kenya. Revue d'Hydrobiologie Tropicale 22: 21-23.

Dadzie, S. \& P. Aloo, 1990. Reproduction of the North American black bass Micropterus salmoides (Lacépède) in equatorial Lake Naivasha, Kenya. Aquaculture and Fisheries Management 21: 49-58.

Delaney, D. G. \& B. Leung, 2010. An empirical probability model of detecting species at low densities. Ecological Applications 20: 1162-1172.

Hamley, J. M., 1975. Review of Gillnet Selectivity. Journal of the Fisheries Research Board of Canada 32(11): 1943-1969.

Harper, D. M., 1987. The ecology and distribution of Zooplanktons in lakes Naivasha and Oloidien. In Harper, D. M. (ed.), University of Leicester studies on Lake Naivasha ecosystem 1962-1984: Final Report to Kenya Government: 101-121.

Harper, D. M. \& K. M. Mavuti, 2004. Lake Naivasha, Kenya: Ecohydrology to guide the management of a tropical protected area. Ecohydrology \& Hydrobiology 4: 287-305.

Hickley, P. \& D. M. Harper, 2002. Fish community and habitat changes in the artificially stocked fishery of Lake Naivasha, Kenya. In Cowx, I. G. (ed.), Management \& Ecology of Lake and Reservoir Fisheries. Blackwell Scientific Publications, Oxford: 242-254.

Hickley, P., R. Bailey, D. M. Harper, R. Kundu, M. Muchiri, R. North \& A. Taylor, 2002. The status and future of the Lake Naivasha fishery Kenya. Hydrobiologia 488: 181-190.

Hickley, P., S. M. Muchiri, J. R. Britton \& R. R. Boar, 2004. Discovery of carp, Cyprinus carpio, in already stressed fishery of Lake Naivasha, Kenya. Fisheries Management and Ecology 11: 139-142.

Hubble, D. S., 2000. Controls of primary production in Lake Naivasha, a shallow tropical freshwater. PhD Thesis, Leicester University, Leicester.

Hubble, D. S. \& D. M. Harper, 2002. Phytoplankton community structure and succession in the water column of Lake Naivasha, Kenya: a shallow tropical lake. Hydrobiologia 488: 89-98.

Hugueny, B. \& D. Paugy, 1995. Unsaturated fish communities in African rivers. American Naturalist 146: 162-169.

Iguchi, K., K. Matsuura, K. M. McNyset, A. T. Peterson, R. Scachetti-Pereira, K. A. Powers, D. A. Vieglais, E. O. Wiley \& T. Yodo, 2004. Predicting invasion of North American basses in Japan using native range data and a genetic algorithm. Transactions of the American Fisheries Society 133: 845-854.

Khan, T. A., M. E. Wilson \& M. T. Khan, 2003. Evidence of invasive carp mediated trophic cascade in shallow lakes of western Victoria, Australia. Hydrobiologia 505: 465-472.
Kitaka, N., D. M. Harper \& K. M. Mavuti, 2002. Phosphorus inputs to Lake Naivasha, Kenya, from it catchment and the trophic state of the lake. Hydrobiologia 488: 73-80.

Lowe-McConnel, R. H., 1999. Ecological Study of Tropical Fish Communities. University of São Paulo, São Paulo: $534 \mathrm{pp}$.

Mavuti, K. M., 1990. Ecology and role of zooplankton in the fisheries of Lake Naivasha. Hydrobiologia 208: 131-140.

Muchiri, S. M. \& P. Hickley, 1991. The fishery of Lake Naivasha, Kenya. In Cowx, I. G. (ed.), Catch Effort Sampling Strategies: Their Application in Fresh Water Fisheries Management. Blackwell Scientific Publications, Oxford: 382-392.

Muchiri, S. M., J. B. P. Hart \& D. M. Harper, 1995. The persistence of two introduced tilapia species in Lake Naivasha Kenya in the face of environmental variability and fishing pressure. In Pitcher, T. J. \& P. J. B. Hart (eds), The Impact of Species Changes in African lakes. Chapman Hall, London: 299-320.

Noble, R. A. A., I. G. Cowx, D. Goffaux \& P. Kestemont, 2007. Assessing the health of European rivers using functional ecological guilds of fish communities: standardising species classification and approaches to metric selection. Fisheries Management and Ecology 14: 381-392.

Ojuok, J. E., M. Njiru, J. Mugo, G. Morara, E. Wakwabi \& C. Ngugi, 2007. Increased dominance of common carp, Cyprinus carpio (L): the boon or the bane of Lake Naivasha fisheries? African Journal of Ecology 46: 445-448.

Oluoch, A. O., 1990. Breeding biology of the Louisiana red swamp crayfish Procambarus clarkii Girard in Lake Naivasha, Kenya. Hydrobiologia 208: 85-92.

Oyugi, D. O., D. M. Harper, M. J. Ntiba, S. M. Kisia \& J. R. Britton, 2011a. Management implications of the response of two tilapiine cichlids to long-term changes in lake level, allodiversity and exploitation in an equatorial lake. Ambio 40: 469-478.

Oyugi, D. O., J. Cucherousset, M. J. Ntiba, S. M. Kisia, D. M. Harper \& J. R. Britton, 2011b. Life-history traits of an equatorial common carp Cyprinus carpio populations in relation to thermal influence on invasive populations. Fisheries Research 110: 92-97.

Oyugi, D. O., 2012. Ecological impacts of the invasive common carp (Cyprinus carpio L. 1758), on naturalised fish species in Lake Naivasha, Kenya. Unpublished PhD Thesis, School of Biological Sciences, University of Nairobim, Nairobi: 279 pp.

Pallant, J., 2007. A Step by Step Guide to Data Analysis Using SPSS Version 15. SPSS Survival Manual, 3rd ed. Open University Press, Maidenhead: 335.

Raburu, P. O., K. M. Mavuti, F. Clark \& D. M. Harper, 2002. Population structure and secondary productivity of Limnodrillus hoffmesteri Claparede and Branchiura sewerbyi Beddard in the profundal benthos of Lake Naivasha, Kenya. Hydrobiologia 488: 153-161.

Schoener, T. W., 1983. Field experiments on interspecific competition. The American Naturalist 122: 240-285.

Siddiqui, A. Q., 1977. Lake Naivasha fishery, Kenya, and its management together with a note on feeding habits of fishes. Biological Conservation 12: 217-227. 
Siddiqui, A. Q., 1979. Reproductive biology of Tilapia zilli (Gervais) in Lake Naivasha, Kenya. Environmental Biology of Fishes 4: 257-262.

Silvano, R. A. M., B. D. do Amaralc \& O. T. Oyakawad, 2000. Spatial and temporal patterns of diversity and distribution of the Upper Juru'a River fish community (Brazilian Amazon). Environmental Biology of Fishes 57(25-35): 2000.

Smart, A. C., D. M. Harper, F. Malaisse, S. Schmitz, S. Coley \& A. C. Gouder de Beauregard, 2002. Feeding of the exotic
Louisiana red swamp crayfish, Procambarus clarkii (Crustacea, Decapoda), in an African tropical lake: Lake Naivasha, Kenya. Hydrobiologia 488: 129-142.

Weber, M., M. L. Brown \& D. W. Willis, 2010. Spatial variability of common carp populations in relation to lake morphology and physicochemical parameters in the upper Midwest United States. Ecology of Freshwater Fish 19: 555-565.

Wetlands International, 2003. Lake Naivasha 1KE002 [available on internet at http://www.wetlands.org/RSIS]. 